\title{
Perception of EFL Among Stalk Holders: Four Selected Government Primary Schools of Wolaita and Dawro Zone in Focus, SNNPR, South West Ethiopia
}

\author{
Mesfin Mekuria Dangore \\ Department of English Language and Literature, Wolaita Sodo University, Sodo, Ethiopia
}

Email address:

mesfinmekuria86@gmail.com

\section{To cite this article:}

Mesfin Mekuria Dangore. Perception of EFL Among Stalk Holders: Four Selected Government Primary Schools of Wolaita and Dawro Zone in Focus, Snnpr, South West Ethiopia. English Language, Literature \& Culture. Vol. 4, No. 1, 2019, pp. 23-31.

doi: $10.11648 /$ j.ellc. 20190401.14

Received: April 3, 2019; Accepted: May 14, 2019; Published: May 29, 2019

\begin{abstract}
In a global society, politics, culture and economics are closely interdependent and higher level education has a responsibility to cultivate and equip professionals with the skills to meet the international competitive environment. English is everywhere in Ethiopia's everyday life, as opposed to indigenous languages, which are mostly hidden. The diffusion of English makes its learning mandatory to aspire to a better social and economic life. Nevertheless, this contextual 'imposition' highly influences perceptions and attitudes we have towards English language. This may also create a strong barrier to the whole language learning process. The aims of this study were (1) to identify how stockholders perceive English as a Foreign Language/English as a Second Language (EFL/ESL) teaching learning processes (2) to examine the roles that stockholders play at the required levels at schools, and (3) to investigate factors that contribute to the perception of stockholders in EFL/ESL teaching-learning processes. For this purpose, 267 students were selected from 40 sections and filled the questionnaire. To get 267 students, seven top achieving students were chosen from 40 sections. Moreover, 16 English teachers, 32 parent-teacher association members, 24 school principals, 16 education officials, 16 supervisors and 40 focus group discussants were selected using availability sampling from four schools. Closed- ended and open- ended questionnaire, video-recording, focus group discussions, and semi-structured interviews were used for data gathering, and the data gathered through these tools was analyzed quantitatively and qualitatively. Based on student surveys in four schools, this paper accented positive perceptions and attitudes towards English language learning, and highlighted the past and the effects of linguistic imperialism. However, based on the evidences found onteaching and learning, teaching English in four schools has been unsatisfactory. The findings further revealed that students, parents, teachers, supervisors, educational experts, and school principals have a positive attitude and perception to English language learning, but they reported that there were factors that impede students' English language learning and the teachers' classroom pedagogy. The data in this study also showed that well-designed teacher preparation is important as the component of ongoing learning and development, and can be a powerful vehicle for preparing teachersto implement new curriculum and innovative teaching methods. In short, this work opened the discussion on how these attitudes could be managed in the classroom, and offered possible directions for future research in intercultural language learning.
\end{abstract}

Keywords: Perception, Stalkholders, EFL/ESL, Primary Schools

\section{Introduction}

English, which is considered to be an important language to get involved in this ever globalizing world, needs more attention, especially in the education sector in Ethiopia. However, this objective doesn't seem to be fully achieved [1]. As mainly stated recently, perhaps assumed to continue in the future, English is the language of the globe. But the changes that English Language Education has witnessed, from a teacher-centered pedagogy to a more learner-centered education, from a textbook-based teaching to a task-based approach, from a summative assessment to a formative assessment reflect educators commitment and teachers concern in an effort to find an appropriate methodology, but 
teachers and learners of foreign languages may or may not share similar perceptions toward English language pedagogy [2-3]. This change has also been practiced for many decades as the researcher referred different documents related to this paper. Eventhough these changes took place in different times and regimes, English has gained importance in Ethiopia since 1940s. The need for English language arose from the desire to establish contact with the outside world and the introduction of modern education to Ethiopia offered to students as a subject beginning from elementary to high school and preparatory levels. In recognition to this, the language has received due attention in that it has been serving the world in many ways. It also serves asmother tongue and medium of communicationfor native speakers. In contrast, non-English speaking countries use it as a foreign language for trade, exchange of culture, values and other communication situations. In this regard, it is stated that '...learning English language is enjoying a prestigious position in many countries since the end of World War II [45]. It is neither a national nor an official language in Latin America but it is the most widely taught foreign language at all stages of educational system'[6]. The same is also true to Ethiopia. In connection to this argument, Depreli argued the challenges of English in school practicum, but he stated that English language has become a major medium for communication across borders globally and is seen nowadays as the medium of communication not only for business but also for academic purposes. However, teacher educational programs have been the focus of criticisms, particularly with regard to how they balance theory and practice [7]. This is one indication of the place of English language in schools. The author also found out that students, especially in rural Ethiopia, have little chance to use English language in their daily lives[8-9]. Nowadays, there is a widely prevailing complaint among English language teachers, trainers, and other stalkholders that many students, even on the completion of university education, are far from the standard in their English language ability. One possible factor seems to be the failure to use classroom assessment feedback, but English language continues to own much more place and center of different curricula. In the nation's education policy, it has been given due attention, place and recognition for the diversity that has been prevailing. Therefore, English is boldly given a position of stronger hold as regions of the country have been given autonomous right to exercise and choose medium of instruction that suits their respective cultural background and the existing need of the students. In this regard, some of the regions nowadays use English as their medium of instruction from the primary schools up to colleges, Universities, research centers as a communication tool. Most highly and importantly, the place of English in Ethiopia increases from time to time. In this case, the country is using English as the best alternative and as a tailored mediator for diversity matters taking the advantage of its worldwide credence.

Understanding the clear place and purpose of English, which has irreplaceable advantage and importance in
Ethiopian context, is unquestionable. The education and training policy and its implementation in Ethiopia states that secondary and higher education is given with English as the language of instruction. In this instance, it is necessary to improve the students' mastery of the language". As the above statement vividly speaks out, in the Ethiopian context, the medium of instruction or the language of instruction in primary education system is changed from indigenous languages to English. This in turn shows that the levels where English is given as a language of instruction are still paramount important for the attainment and implementation of the desired goals and even the education policy matters in broad.

When we see the mastery and strong command of the English language as a medium of instruction at primary schools, it is fragile. This case may or may not differ from school to school, department to department, and so on. Without discrimination, may be the level of perception towards English as medium of instruction, can be taken as more or less the same, though it needs further investigation and judicious scrutiny. Here, something to be emphasized is that at primary schools, for example, a student placed to take English as a major course seems to have different perception or attitude, but from our past and present experiences as teachers, what we could observe is, except for the difference in shouldering the responsibility by students, it seems to be found similar.

My concern here is that as participants and as instructors, and part of the society I am living in, primary schools are assumed to be the best places to lay a good foundation for the future levels of education and in doing so, they bring an overall betterment of a nation. If there is no appropriate base from the bottom, changing the upward may be challenging. In this instance, this research work focused on the perception of the stockholders on EFL/ESL teaching learning process at four selected primaryschools, which are the early bases in our country and elsewhere. In reviewing for similar works, I hardly found works that have direct focus in South Ethiopia, except for some researchers referred from universities and colleges. Therefore, there is a gap in this area that needs to be filled. Hence, this study was conducted to achieve the following research objectives:

1. To identify how stockholders perceive EFL/ESL teaching learning processes

2. To examine the roles that stockholders play at the required levels of schools

3. To investigate factors contributing to the perception of stockholders in EFL/ESL teaching learning processes.

\section{Methods}

\subsection{Design of the Study}

This research followed a descriptive research approach to depict people, situations, events, and conditions as they currently existed [10-11]. The study is more qualitative in nature, but frequencies and percentages were used for 
quantitative parts. Different arguments put forward showed thatdescriptive research studies are designed to obtain pertinent data and, whenever possible, to draw valid general conclusions from the facts discovered. In this regard, percent and frequency counting was employed for the quantitative analysis, where as the data collected through interview, video-recording, focus group discussion, observation results, and all open-ended data were analyzed qualitatively.

\subsection{Participants and Sampling Technique}

The subjects of the study were school principals, English teachers, parents, grade 8 students, Wereda education officers, and supervisors from four selected schools ofWolaita and Dawro zone enrolled in 2018 academic year. In each class, there were about 75-80 students, which could be taken as a very large class size. It is suggested that for descriptive studies, a common recommendation is to sample approximately $10-20 \%$ of the respondents or top achievers of the respondents [12]. In this regard, seven top achieving students were chosen from 40 sections; as a result, 267 students filled the questionnaire. Moreover, 16 English teachers, 32 parent-teacher association members, 24 school principals, 16 woreda education officials, 16 supervisors and 40 focus group discussants were selected using availability sampling from four schools. According to Creswell (2012: 145), "In availability sampling (i.e, the researcher selects individuals because they are available, convenient, and represent some characteristic the investigator seeks to study."In the other way, four primary schools found in Wolaita and Dawro zone were purposefully selected as representative research setting [3].

\subsection{Data Collection Tools}

The following tools were used to collect data on the stockholders' perception in EFL/ESL teaching-learning process. First, questionnaire was prepared in English and translated into mother tongues, which are the languages of students and their parents in the study areas. Questionnaire is a popular means of collecting all kinds of data in research [910]. Koul (ibid) further argued that questionnaire is widely used in educational research to obtain information about certain conditions and practices, and to inquire into opinions and attitudes of an individual or a group. To this end, both closed-ended and open ended questions in a Likert scale and YES/NO questionnaire items were used to gather information from the participants. The second data collection tool was interviewto obtain deeper information, and it was employed to gather information from school principals, students' parents, English teachers, Wereda education officers and supervisors of the sample schools. In this case, semistructured interview questions were employed to elicit the feelings of all interviewees who were participated in process of interviewing. In this regard, items translated into mother tongue were administered to parents and those in Englishwere administeredto principals, English teachers,
Wereda education officers, and supervisors. Focus Group Discussion (FGD) was also employed so as to depict students' perceptions and opinions about the EFL/ESL teaching learning process freely. Though the suggested size of focus group discussants varies, in this research, a minimum of eight (8) to twelve (12) students were participated. Focus group can reveal a wealth of detailed information and deep insight and allow students to thoughtfully answer questions in their own words and add meaning to their answers. Video-recording was also used to support the data [14].

\subsection{Data Analysis}

In analyzing the data, both qualitative and quantitative methods were used. It was made clear earlier that percentage and frequency counting was employed to analyze quantitative data, whereasdata collected through observation, interview, and video-recording were analyzed qualitatively. In relation to this analysis, simple percentage is the most widely used descriptive statistics, which could yield valuable quantitative and qualitative results and is relevant in quantitative illustration because it is useful in simple explanation of basic differences or similarities that could exist between or among the variables under observation [11].

\section{Ethical Issues and Procedures}

In taking into account aforementioned information gathering tools, all possible means were used to communicate with different respondents in the four selected schools so as to get valid and reliable data. In this regard, positive and cooperative environment were created in the first round contact with all school principals and adjustments were made to achieve getting actual data from desired participants-teachers, students, parents, principals, Wereda education officers and supervisors. Next, with the adjusted time interval, questionnaire was distributed to students; interview was held with parents, English teachers, principals, Wereda education officers and supervisors; focus group discussion was carried out with selected students. They all were informed about the confidentiality of data they had provided.

\section{Results and Discussions}

Theoretically, it is assumed that perception of the students and teachers are main determinants of performance, success and accomplishments in education. Having good perception to EFL and its teaching-learning processes leads to effectiveness amongstalkholders. In line to these, the findings in this study describe the existing perception, attitude, and belief of four selected schools teachers and learners. The table below shows the statistical value of the responses of the respondents. 


\subsection{Analysis of Students' Questionnaire from Four Primary Schools}

Table 1. Questionnaire items to identify how stockholders perceive EFL/ESL teaching learning processes.

\begin{tabular}{|c|c|c|c|c|}
\hline Itemno & Questionnaire Items & Alternatives & Frequency (f) & $\%$ \\
\hline \multirow{2}{*}{1.} & \multirow{3}{*}{ I know that English language is a key for my academic success. } & A. yes & 180 & 67.41 \\
\hline & & B. no & 87 & 32.58 \\
\hline Total & & & 267 & 100 \\
\hline \multirow{2}{*}{2.} & \multirow{2}{*}{ I give due attention for English language learning. } & YES & 153 & 57.30 \\
\hline & & NO & 114 & 42.7 \\
\hline Total & \multirow{4}{*}{ English language has no different place for me than other subjects. } & & 267 & 100 \\
\hline \multirow{2}{*}{3.} & & YES & 170 & 63.7 \\
\hline & & NO & 97 & 36.32 \\
\hline Total & & & 267 & 100 \\
\hline \multirow{2}{*}{4.} & \multirow{2}{*}{ I equally value English language with other subjects } & Yes & - & - \\
\hline & & No & 267 & 100 \\
\hline Total & \multirow{4}{*}{ I ignore English language because I don't have good background knowledge. } & & 267 & 100 \\
\hline 5 & & YES & 160 & 60 \\
\hline 5. & & NO & 107 & 40 \\
\hline Total & & & 267 & 100 \\
\hline \multirow[t]{2}{*}{6.} & For there was no room to exercise English language before now, I fear to use English language. & YES & 267 & 100 \\
\hline & Total & & 267 & 100 \\
\hline \multirow{3}{*}{7.} & \multirow{2}{*}{ I simply found English language difficult and dislike it. } & YES & 140 & 52.43 \\
\hline & & NO & 127 & 47.56 \\
\hline & Total & & 267 & 100 \\
\hline \multirow{3}{*}{8.} & \multirow{2}{*}{ I like English language very much because I score good mark in it. } & YES & 50 & 18.8 \\
\hline & & NO & 217 & 81.27 \\
\hline & Total & & 267 & 100 \\
\hline \multirow{3}{*}{9.} & \multirow{2}{*}{ I practice English language always, so that I am confident to use it in my daily life. } & YES & - & - \\
\hline & & NO & 267 & 100 \\
\hline & Total & & 267 & 100 \\
\hline \multirow{3}{*}{10.} & Because I have no chance to practice English outside the classroom, I take using English & YES & 201 & 75.2 \\
\hline & language as a worthless issue. & NO & 66 & 24.8 \\
\hline & Total & & 267 & 100 \\
\hline
\end{tabular}

The above table discussed the questionnaire items that were carried out to identify how stalkholders perceive EFL/ESL teaching-learning process. To this end, about ten closed-endedobjective questions were designed and distributed to 267 sample student populations. These questionnaire items asked questions on the students' position regarding English as a medium of instruction in the classroom, or out of the classroom; the students' attention level to the language-do they like or not?; comparing English with other subjects; concepts on the situations to practice English, and the answers to these items were presented in a descriptive way. In this regard, about 267 students answered the questionnaire items. Different arguments put forward by different Ethiopian scholars suggested that for any student to be successful in academics, he/she must have a good command of English language regardless of the field of the study students join. In line with this argument, about $180(64.41 \%)$ of the respondents discussed that English language is a key to their classroom success, while half of the respondents $87(32.58 \%$ ) said No. This scenario indicated that English language has a paramount role in the students' life. But the major criticism sometimes pushes students back from mastering good command of English. They may be considered as a boasting person when they try speaking in English, but there is one saying that "If you send your students to an international schools, you will lose your student." There are also several positive or negative feedbacks that may influence perception toward English skills. According to item number 2, about 153(57.30\%) subjects argued that they give due attention to an English language, but other considerable portion of respondents $114(42.7 \%)$ said NO. However, the question must be who is responsible to this fact-student or the teacher? It is argumentative and needs further investigation. Another question that was forwarded to respondents reads that English language has no different place for them than other subjects. Based on this item, 170(63.7\%) of the subject students selected YES, and the other half of the respondents, i.e, $97(36.32 \%)$ selected NO. Moreover, the total number of students $267(100 \%)$ asserted that they do not equally value English language with other subjects. In opposition to this argument under item number 5, about $160(60 \%)$ respondents chose YES on the item that reads, "I ignore English language because I don't have good background knowledge", and about $107(40 \%)$ subjects claimed NO. Another question stated on item 6 showed that there was no room to exercise English language before now; consequently, all respondents $267(100 \%)$ claimed that they fear to use English language due to lack of actual practice to develop the language. Item 7 reads "I simply found English language difficult and dislike it", and the student respondents, i.e. about 140(52.43\%), out of the total subjects, replied that they simply fear English language though about $127(47.56 \%)$, which accounts half of the respondents, answered No. Minimum respondents 
$50(18.8 \%)$ claimed in the idea that they like English language very much because they score good mark in it, but about $217(81.27 \%)$ respondents answered No claiming their poor mark in exams. In fact, when students score lowest mark in exams, they consequently hate that subject. Informants also reported that they do not always practice English language. In relation to this discussion, item number $9 \& 10$ were asked to get the students' answer whether they practice speaking in English, or not. In this regard, it was found that all selected respondents $267(100 \%)$ portrayed they do not have chance to practice English outside the classroom, and as a result, the students perceive using English language worthless. Scholars, moreover, argued that teachers' self-efficacy belief affects their work and has a direct relation with their learners' motivation and achievement. Teachers' low level of selfefficacy belief affects their practice and their learners' motivation and achievement negatively (Mojavezi and Tamiz, 2012). The study also explicitly stated that teachers' self-efficacy belief positively affects students' achievement [Solomon, 2018:5). Therefore, it is also true that perception towards English language may be affected by different factors.

The above chart clearly showed scenarios concerning the use of English language, especially in four selected schools. The data obtained through interviews and focus group discussions also showed that the teachers' motivation to encourage use of English in and out of the actual teachinglearning situation, teachers' poor pedagogy, teachers' poor training system applied in schools, the students' mothertongue dominated linguistic background influence and negative perception to the target language are some of the triggering factors for the existing problem. By and large, the practice of classroom assessment in adjusting English language teachers' teaching techniques, the classroom assessment techniques teachers employed in the classroom, for what purpose they used, the kinds of feedbacks they obtained while they assess their students' English using different classroom assessment techniques, and whether they used the feedbacks to adjust their English language teaching techniques or not are some of the factors that may determine, to the large extent, the perception of EFL among stalkholders.

Table 2. Responses on examining the roles that stockholders play at the required levels of schools[Note:SA=strongly agree; $A=a g r e e ; D=d i s a g r e e ; S D=$ strongly disagree].

\begin{tabular}{|c|c|c|c|c|}
\hline Item no & Questionnaire Items & Alternatives & Freq & $\%$ \\
\hline \multirow{4}{*}{11.} & \multirow{4}{*}{ Because teachers disregard may attempt to use English in classrooms, I dislike English language. } & SA & 0 & 0 \\
\hline & & A & 7 & 2.7 \\
\hline & & $\mathrm{D}$ & 100 & 37.45 \\
\hline & & $\mathrm{SD}$ & 160 & 60 \\
\hline \multirow[t]{2}{*}{ Total } & \multirow{6}{*}{ I like English language and like to use it in and outside the classrooms. } & & 267 & 100 \\
\hline & & a. SA & 180 & 67.41 \\
\hline \multirow{3}{*}{12.} & & b. A & 67 & 25.0 \\
\hline & & c. D & 20 & 7.49 \\
\hline & & d. SD & - & - \\
\hline \multirow[t]{2}{*}{ Total } & & & 267 & 100 \\
\hline & \multirow{4}{*}{ The way teachers teach English discourages me to fully exercise English language. } & SA & 267 & 100 \\
\hline \multirow{3}{*}{13.} & & A & - & - \\
\hline & & $\mathrm{D}$ & - & - \\
\hline & & SD & - & - \\
\hline \multirow[t]{2}{*}{ Total } & & & 267 & 100 \\
\hline & \multirow{4}{*}{ The supports I get from teachers help me practice English language fully. } & a) SA & - & - \\
\hline \multirow{3}{*}{14.} & & b) A & & \\
\hline & & c) $\mathrm{D}$ & 201 & 75.2 \\
\hline & & d) SD & 66 & 24.8 \\
\hline \multirow[t]{2}{*}{ Total } & \multirow{5}{*}{ Lack of supportive materials in and outside the classrooms made me dislike English language. } & & 267 & 100 \\
\hline & & SA & 255 & 95.50 \\
\hline \multirow{3}{*}{15.} & & A & 12 & 4.5 \\
\hline & & $\mathrm{D}$ & - & - \\
\hline & & $\mathrm{SD}$ & - & - \\
\hline \multirow[t]{2}{*}{ Total } & & & 267 & 100 \\
\hline & \multirow{4}{*}{ The learning environment made me dislike English language. } & SA & 199 & 74.53 \\
\hline \multirow{3}{*}{16.} & & A & 68 & 25.46 \\
\hline & & $\mathrm{D}$ & - & - \\
\hline & & SD & - & - \\
\hline \multirow[t]{2}{*}{ Total } & \multirow{6}{*}{ My parents don't like when I speak in English language. } & & 267 & 100 \\
\hline & & SA & - & - \\
\hline \multirow{3}{*}{17.} & & A & - & - \\
\hline & & $\mathrm{D}$ & - & - \\
\hline & & SD & 267 & 100 \\
\hline \multirow[t]{2}{*}{ Total } & & & 267 & 100 \\
\hline & \multirow{3}{*}{ My friends disregard when I practice English language in and outside the classrooms. } & SA & 116 & 43.4 \\
\hline \multirow[t]{2}{*}{18.} & & A & 50 & 18.8 \\
\hline & & $\begin{array}{l}\mathrm{D} \\
\mathrm{SD}\end{array}$ & 101 & 37.9 \\
\hline
\end{tabular}




\begin{tabular}{|c|c|c|c|c|}
\hline Item no & Questionnaire Items & Alternatives & Freq & $\%$ \\
\hline \multirow[t]{2}{*}{ Total } & \multirow{5}{*}{$\begin{array}{l}\text { Because there was no role model in and outside the classrooms, made me disregard English } \\
\text { language. }\end{array}$} & & 267 & 100 \\
\hline & & SA & 210 & 78.7 \\
\hline \multirow{3}{*}{19.} & & A & 50 & 18.8 \\
\hline & & $\mathrm{D}$ & 7 & 2.7 \\
\hline & & SD & - & - \\
\hline \multirow[t]{2}{*}{ Total } & & & 267 & 100 \\
\hline & \multirow{4}{*}{ I dislike the teaching methodology of English teachers and hate learning of English language. } & SA & 80 & 30 \\
\hline \multirow{3}{*}{20.} & & A & 100 & 37.45 \\
\hline & & $\mathrm{D}$ & 60 & 22.4 \\
\hline & & SD & 27 & 10.1 \\
\hline \multirow[t]{2}{*}{ Total } & \multirow{6}{*}{ I simply fear English and dislike it and disregard myself. } & & 267 & 100 \\
\hline & & SA & 240 & 90 \\
\hline \multirow{3}{*}{21.} & & A & 20 & 7.4 \\
\hline & & $\mathrm{D}$ & 7 & 2.7 \\
\hline & & SD & - & - \\
\hline Total & & & 267 & 100 \\
\hline
\end{tabular}

In the way to ask about the students' responses on examining the roles that stalkholders play at the required levels of schools in teaching-learning English, about 11 lickert-scale-based questions were designed and distributed to the students. In this regard, about $7(2.7 \%)$ students agreed that teachers disregardtheir attempts to use English in the classroom due to poor payment and lack of support, and students are found reporting that they dislike using English in the classroom. In opposition to this argument, 100(37.45\%) respondents disagreed with the given question, whereas about $160(60 \%)$ students strongly disagreed the idea that teachers disregard the students' attempt in the classroom and it can be deduced that, in our context, our partners are found not ok when we try to use English language in and outside the classroom. In the other way, according to item 12 , in table 2 , majority of the respondents reported as if they like to use English language outside the classroom while the remaining few respondents are not firm in this idea. As the science of the classroom pedagogy further shows, teaching methodologies used in the classroom are key to the students' success in language learning. In this regard, all respondents $267(100 \%)$ indicated that the way teachers teach English discourages students to fully exercise English language. Students get confusing supports from teachers; they are not ok with teachers; teachers are not active enough in supporting students-this is an issue in the current Ethiopian Education strategies. So, item number 13 has no strong response on the idea that the supports students get from teachers help them fully practice English language. Studies and research, however, show that no method of teaching can work effectively in all settings. A method that confirms to be successful in one setting might not be so in another. For a method to work effectively, it should involve other factors, such as task, students, and teacher [7]. A method is "a set of activities to be carried out in the classroom, and to the theory, belief, or plausible concept that informs those activities". This definition indicates that to work effectively, a method should combine techniques and approaches and a teacher should have sense of plausibility. Item number 13 , in table 2 , thus, showed that language teaching methods are not okay for the students to master English language. In the same way, though it has been said a lot, according to item number 15 , about $255(95.50 \%)$ respondents showed that lack of supportive materials in and outside the classroom made students dislike English language while few 12(4.5\%) reflected less concern. The datum showed that students who learn English at urban centers are not found to be equal with students who are attending English classes at rural areas in Ethiopia, and the same seems to be true to other regional state schools. In connection to this argument, about valuable number of students $199(74.53 \%)$ strongly agreed that the learning environment made learners to dislike English language, but few students 68(25.46\%) agreed to some extent in the given item. One hypothetical item set was "My parents dislike when I speak in English language." All students strongly disagreed. Item 17 indicated that parents like their students to use English. The contribution of the classroom friends is low to develop and improve English language. According to item 18, about 116(43.4\%) subjects showed positive answer to this item, but few 50(18.8\%) students agreed as if friends' attitude affects the development of English language, whereas about 101 (37.9\%) respondents strongly disagreed on the item that reads "My friends disregard when I practice English language in and outside the classrooms." In this regard, the language teaching principle states that students learn what they are taught. Role models are good cornerstones to learn English language but the above item argued in the opposite direction. This idea is related to item 19, but most of the respondents $210(78.7 \%)$ argued that there is no role model for them to develop their English language. Item 20 in tables 2 read that, "I dislike the teaching methodology of English teachers and hate learning of English language." To this question, out of the total 267 student respondents, about $80(30 \%)$ students agreed on the given argument, but $100(37.45 \%)$ respondents claimed positively though other halves disagreed (i.e. 60(22.4\%) \& $27(10.1 \%)$. The worst idea is also indicated under item 21 in that all students $240(90 \%)$ SA, 20(7.4\%),\& 7(2.7\%) feared English and disliked themselves.

In short, reluctant teachers who do not support their students, lack of situations to use English, bad classroom methodology, lack of authentic materials, the environment where schools are located, parents, peer pressure, and lack of role model are some of factors that may lead students not to 
develop good command of English. Stalkholders' perception towards English language can be seen from these major factors.

\subsection{Analysis of Focus Group Discussions}

FGD is very important in social sciences research $[6,10$, $13,14]$. The writer of this paper held discussions with group of students in the four selected schools. No matter how each of the groups held discussions with the researchers on different days, what all of discussants said about the use of English language classroom was almost the same. As it was described in methodology section, focus group discussion can reveal a wealth of detailed information and deep insight. Again, in verifying its giving of freedom or ease to participants, when well executed, a focus group creates an acceptable environment that puts participants at ease allowing them to thoughtfully answer questions in their own words and add meaning to their answers [12]. The first question reads "How do you perceive/value English language in your opinion?" The discussants argued that they do have a positive attitude towards English language though respondents have been facing varieties of problems-lack of supportive material to develop fluency of English language. FG discussants also argued that they consider English as their key subject in varieties of ways. However, the discussants reported that they face several problems, such as shyness to speak in public, lack of enough vocabularies according to different contexts, lack of audio-videos, CD/DVD cassettes (recorded materials), and many more, $\&$ due to this reason, there are some students who joke and don't attend classes. Every respondent replied NO to the question that reads "Do you think that you have a good command of English language?" And this scenario needs adequate attention from concerned bodies. Finally, the discussants recommended that further action should be taken to mitigate the students' language problem. Students should be given much opportunity in developing their speaking skill, and mother tongue influence should take much attention $[12,13,17,18]$.

\subsection{Analysis of English Teachers' Interview Questions}

From four selected secondary and preparatory schools, 10 English teachers were interviewed based on the familiarity of the respondent teachers with the researcher because they know the researcher. Based on this selection, the researcher believes that he had derived pertinent data for 7 semistructured interview questions. Five of the questions were designed based on the different arguments forwarded concerning the use of English and the perception of teachers and their students on EFL/ESL so as to draw literature based answers from interviewees. In reaction to how teachers view the scholar's argument that using the students' exposure to the target language, the first teacher responded that his students do have a positive attitude towards English language. Concerning the second question, interviewers claimed that there is lack of good atmosphere in mastering English language because students couldn't get adequate exposure to the target language. The next question that reads, "Do you encourage your students to practice English everywhere?" and teachers at Boditi primary school boldly argued that they highly support students to practice English everywhere, but because of several challenges, students do not have an adequate exposure to the language. In relation to this item, teachers replied that there is an English day twice a week though some criteria lacks. In this regard, the major cause for the negative attitude towards English language has been developed from the students' side and students waste their golden time joking. In general, the data indicated that teachers have a positive attitude towards English language though there are gaps. The remedy, suggested by the teacher interviewees, should be creating the situation that students and the whole communities are exercising with regard to perception of English language. Language laboratories should be established; students should be supported psychologically and materially.

\subsection{Analysis of Interview Question Results with Education officers}

Woreda education officers have direct or an indirect connection with every school academic progress, and they are found to be relevant to be interviewed in this research [16]. The first question to one of the woreda education officers reads "Do you think that students in your weredas have positive attitude towards English language? Why? Why not?" And the respondent answered that majority have a positive attitude to English language, but few students hate it because they didn't get a good baseline on the subject-poor teaching, poor teachers to train students, poor material in English, which is based on the students' passive acceptance of the content knowledge, and many other challenges. The data from respondents showed that students who are learning at urban areas have a good base than rural students. The second interview question to these respondents was "Do you believe that there is good atmosphere to practice English in and outside the classrooms? How?" And the subjects replied that there is no good atmosphere in and outside the classroom because students whose elementary school background is mother tongue-based instruction don't easily accept what they are told to do so; there is no language laboratory; there are teachers who do not like teaching profession, and the school environment though education officers support and maintain good English. Therefore, to the question that reads "What do you think is the major cause for the negative attitude towards English language?" the respondents answered that all mentioned negative factors affect the students' perception to an English language.

\section{Conclusion}

Learning for no obvious reason, or at least, learning for passing exam purpose have no positive effect in the educational framework prescribed by the principles underlying sustainable learning societies. As for English as a subject matter, it is generally thought out as an examination 
subject rather than a necessary component in the general educational programme; a vital vehicle conducive to the building up of a sustainable information society. However, the immediate goal of and the primary motivating force in learning English in Ethiopia is to help pupils and students to pass examinations. Indeed, informants almost overwhelmingly cite using English for higher institution examinations, understanding other subjects, and teachers' enforcement as the primary motive for studying English. Speaking English has also been perceived as the sign of modernity in Ethiopian contexts. This exerts a destructive influence on the language learning process in the sense that English language education as an end in itself.

The overall educational failure of the Ethiopian school and lack of achievement in the English language learning field affecting negatively the students perceptions and motivation towards the new language can be traced back mostly to two types of factors: teacher-related and student related factors. The teacher-related factors include lack of motivation/interest to teach, poor salary which does not encourage teachers to be dedicated, bad classroom teaching methods, and using outdated teaching materials for years. Student-related factors, on the other hand, include lack of motivation to learn, poor family background, distance of schools from home land, peer pressure, and fear of criticisms set students back from having good command of English.

The study of teacher and student perception and thinking has become one of the interests in the field of education, especially in language teaching and learning, as it is a means of understanding teacher behavior in the classroom. Since teaching is a complex process, teachers have to confront with a lot of activities, and in trying to understand how teachers deal with these dimensions of teaching, it is necessary to examine the perception and attitudes which underlie teachers' classroom actions or behavior. In this study, an attempt has been made to dig out perception of EFL among stalk holders towards the English language. The findings of this study generally indicated that the majority of respondents, especially teachers, and students, have favorable attitude towards English language teaching and learning. Teachers' and students' positive perceptions towards English generally refer to international business possibilities, use of a lingua franca, technological development, communication, bilingual education and therefore study abroad possibilities, international job offers, better incomes, more power and respect. Respondents also suggested that speaking English opens the door for admission into various scholarships. Nearly $90 \%$ of Ethiopian learners know that English is extremely important, and almost $99 \%$ of them think that it will help them in their professional growth [7-9].

In general, Ethiopians with a high proficiency level in English are part of the elite. As mentioned before, most of the elite went to private schools where English is taught as a foreign language. Some of them even studied at least a semester abroad or completed a master's degree in a foreign country. This scenario places a negative influence on economically poor students who cannot afford private school fees, and has been point of argument in Ethiopia. It is clear that the growing number of people expressing their desire towards learning English as well as the growing number of schools, state-run or private, offering courses mirror the place English language holds in various fields worldwide. Most well educated Ethiopians believe in the benefits of internationalization and globalization. They also consider English as a lingua franca which helps in international communication. They like buying American or European products because they think their quality is better and because of the social status these products represent. They have a passport and often travel to American or European Center Countries, and usually have good paying jobs and a relatively high social status[16-17]. In addition, this population usually do not mind using English loanwords in Amharic as English is part of their daily life. In the Ethiopian education system, English language is taught as a subject starting from grade three, and it's used as a medium of instruction in the secondary and tertiary levels. As a result, our students in primary schools as well as in institutions of higher learning have a very good reason for learning English. Given the role of English as an international language and its growing use in certain important aspects of Ethiopian life, the students will need to achieve sufficient mastery of the language to enable them to communicate effectively in English socially and in the work place wherever the use of English is necessary. Hence, this implies that for students to be competent in the academic career, they need to be competent in the English language skills. In relation to these explanations, reports from the students' interview data, audio-taped lessons, classroom observation, FGD results, and questionnaire results, it is clear that English is very much essential to the students' current and future academic achievements. In short, it is difficult to realize the intended objectives and practices without considering various factors that could contribute in one way or the other to enhancing learning at any level. This is because educational achievements are the outcomes of interwoven factors. However, economically strong families may send their students either to good local private schools, or to some foreign countries for better education. Economically poor parent do not send their students to any of these schools. Their students do not compete for foreign scholarships; consequently, these students become stereotyped, and develop sense of mentally deranged personality. Thus, strong action should be taken from Ministry of Education (MOE). Moreover, the condition of the classrooms and the number of students do not match in the study areas and this affects the implementation of English learning. Having appropriate class size may not always be possible. The teaching material development should not be the task of one or two experts. It should be the result of cooperative effort of different knowledgeable and skilled professionals. Pedagogical, language and subject experts should be involved in the process of designing teaching modules. Well-trained teachers, who are educated in how to handle EFL courses, should be employed at lower levels because teachers who are 
MA/Msc holders have been employed only in colleges and Universities, but these teachers should also be employed at lower levels to put good baseline on the students' learning.

\section{References}

[1] Surdyanto, A (2016) Students' perceptions of the use of English at a bilingual setting based on their kindergarten language background Journal of ELT Research, 1(2)

[2] Amini Farsani, Mohammad (2016) Depicting EFL Learners' and Teachers' Perception toward Communicative Language Teaching: Voices from Iran Iranian EFL Journal.

[3] Smail Benmoussat, Nabil Djawad Benmoussat (2018) The Teach-to-the-Test Approach: Doing Harm to the Lifelong Educational Paradigm of Algerian EFL Learners English Language and Literature, 3(1), 1-6.

[4] Cohen, A. D (2015) Language Learner strategies: 30 years of research and practice TESOL Quarterly, 49-47.

[5] Geberew Tulu (2014) EFL classroom assessment: Teachers' practice and teaching techniques adjustment in Ethiopia Educational Research and Reviews, 9920), 1071-1089.

[6] Alamri, H. R. H (2018) Challenges in practicum: views and perceptions of EFL pre-service teachers towards fieldexperience skills in real classroom Arab World English Journal, 9(1).

[7] Depreli, E (2014) EFL student teachers' shadowing experience: Is it worth it? Global Journal of Foreign Language Teaching, 41(1), 59-64Retrieved April 3, 2016 from http://www.world-

educattioncenter.org/index.php/GJLLT/article/view/3189

[8] Hailu Abraha (2008) A Study on The English for Ethiopia Grade 11 Students' Books: The Case of Weldu Nugus Secondary School- Quiha. MA Thesis, Addis Ababa University (Unpublished).
[9] Han, L (2010) The advantages and the problems of multimedia-aided English reading instruction Journal of Language Teaching and Research, 1, 320-323.

[10] Mertler, M, Craig A, and Charles. C (2005) Introduction to Educational Research Boston: Pearson Education, Inc.

[11] Shields, Patricia, and Rangarajan, N (2013) A playbook for Research methods: Integrating Conceptual Framework and Project Management Srillwater, OK: New Forums Press.

[12] Barry, W. J (2012) Challenging the Status Quo Meaning of Educational Quality: Introducing Transformational Quality (TQ) Theory Educational Journal of Living Theories, 4, 1-29.

[13] Koul, L (2005) Methodology of Educational Research (3 ${ }^{\text {rd }}$ ed.). Vikas Publishing House PVT LTD

[14] Michale, B, Jane, F Michelle, T \& Kate R (2001) Focus Group in Social Research London: SAGE Publications Ltd.

[15] Creswell, J. W, and Clark, P (2007) Designing and Conducting Mixed Methods Research Thousand Oaks: CA: Sage.

[16] Solomon Kidane (2018) Teachers' and Students' Self-Efficacy Belief and Attitude Towards Hard-CLIL in Ethiopian Vocational Polytechnic Colleges, 3(3), 5.

[17] Ministry of Education (2002) The Education and Training Policy and Its Implementation Addis Ababa: Berhan and Selam Printing Press.

[18] Creswell, JW (2012) Educational Research: Planning, Conducting, and Evaluating Quantitative and Qualitative Research Boston: Pearson Education, Inc. 